\title{
Fatores para Implantação e Desenvolvimento da Gestão por Competências em Agências Reguladoras Federais
}

\author{
Diogo Ribeiro da Fonseca ${ }^{1} \&$ Pedro Paulo Murce Meneses ${ }^{2}$
}

${ }^{1}$ Agência Nacional de Transportes Terrestres, Setor de Clubes Esportivos Sul - SCES, lote 10, trecho 03, Projeto Orla Polo 8, CEP 70200-003, Brasília - DF. E-mail: diogorfonseca@gmail.com

${ }^{2}$ Universidade de Brasília, Campus Universitário Darcy Ribeiro, CEP 70910-900, Brasília - DF.

E-mail: pemeneses@unb.br

ISSN 2448-0479

Resumo - O presente artigo aborda o tema da modernização da gestão de pessoas na Administração Pública Federal no Brasil, referente às políticas de implementação da gestão estratégica por competências como instrumento de desenvolvimento de servidores públicos. $\mathrm{O}$ estudo buscou analisar o processo de implantação do modelo de competências nas Agências Federais de Regulação, de forma a identificar os principais fatores que interferem no processo de institucionalização deste modelo de gerenciamento de recursos humanos. Buscou-se embasamento nos pressupostos da Visão Baseada em Recursos e nas teorias do Novo Institucionalismo para a composição de perspectivas complementares na análise do citado processo. A pesquisa, de abordagem qualitativa e natureza descritiva, foi executada mediante entrevistas semiestruturadas aplicadas a 18 servidores e gestores, atuantes na área de gestão de pessoas, nas 10 agências reguladoras federais. Os relatos foram processados por meio de análise de conteúdo que permitiu identificar, nas entrevistas, 19 fatores contextuais distribuídos em seis categorias. Os fatores descrevem uma combinação complexa de elementos organizacionais e institucionais que proporcionam diferentes trajetórias e capacidades de implantação da gestão por competências em cada agência. Concluiu-se que a gestão por competências encontra-se em um estágio pré-institucional, com poucos casos de sucesso, alta influência do arranjo político organizacional e coexistência, com certa incompatibilidade, de dispositivos burocráticos e gerenciais. Tais fatores institucionais e contingenciais sugerem a necessidade de uma legislação de pessoal mais consistente e integrada, assim como maior patrocínio e orientação do governo para realização das reformas almejadas.

Palavras-Chave - Gestão Estratégica de Pessoas. Gestão Pública. Teoria Institucional.

\begin{abstract}
Fatores para Implantaçáo e Desenvolvimento da Gestáo por Competências em Agências Reguladoras Federais. This article addresses the human resource management practices modernization in Public Federal Administration in Brazil, concerning the policy implementation of strategic competency management as a mean to improve public workforce development. The study aimed to analyze the implementation process of the competency model in the Federal Regulatory Agencies in order to identify the main factors that affect the institutionalization of this human resource management model. Theoretical foundation was based on the Resource Based View and New Institutionalism theories as complementary perspectives in the analysis. The data collection and analysis, of descriptive nature, was performed by semi-structured interviews applied with 18 servers and managers working in the personnel management area, in all 10 federal regulatory agencies. The reports were processed through content analysis, which identified 19 contextual factors divided into six
\end{abstract}


general categories. The factors describe a complex combination of organizational and institutional elements that provide different paths and management capabilities for the implementation of strategic competency management in each agency. The work concludes that competency management stands in a pre-institutionalization stage with few success cases and a higher susceptibility to the organization political environment and coexistence, with relative incompatibility, of bureaucratic and managerial practices. Such institutional and contingential factors suggest the need of a more integrated and consistent personnel legislation as well as better government orientation and patronage towards the implementation of these reforms.

Keywords - Human Resource Management. Public Administration. Institutional Theory.

Recebido em: 05 de maio de 2016.

Aprovado em: 17 de maio de 2016.

\section{INTRODUÇÁO}

A Administração Pública brasileira enfrenta o desafio de responder adequadamente ao posicionamento do Brasil como uma economia em ascensão, com crescente respaldo no âmbito político internacional e cidadãos mais cientes de seus direitos e responsabilidades. À medida que este desafio maior exige do setor público uma estrutura administrativa efetiva, capaz de coordenar políticas estratégicas para o desenvolvimento nacional, emerge o modelo gerencial como forma de superação do modelo burocrático, por meio de práticas mais centradas no desempenho eficiente das atividades-núcleo estatais, com foco nos resultados ao cidadão.

No âmago desta transição, de uma administração burocrática para outra gerencial, também as unidades de recursos humanos sofrem modificaçóes significativas. Entre essas, destaca-se a crescente valorização das competências e conhecimentos tácitos, entáo compreendidos como recursos estratégicos, obtidos e desenvolvidos pelo quadro de servidores públicos. Essa transiçấo tem ocorrido no teor das reformas da administração pública, a partir da década de 1990, nos países mais desenvolvidos, e pode ser relacionada à mudança, mais generalizada, do paradigma funcional de gestão de pessoas para outro de natureza estratégica e integrada.

Nesse novo paradigma, a gestão por competên- cias tem se desenvolvido muito recentemente no setor público brasileiro em funçáo dos resultados positivos observados em outros países, e que, supostamente, atestam seu potencial de replicação no cenário nacional. Conforme dados da Organização para a Cooperação e Desenvolvimento Econômico (OCDE) (2010b), nas administraçôes públicas dos países em que foi implementada - Estados Unidos, França, Holanda, Coréia, Austrália, Canadá e Dinamarca a gestáo por competências possibilitou a criação de uma linguagem comum e consistente entre os subsistemas de gestão de pessoas, o monitoramento das carreiras dos servidores, a gestão de pessoas orientada para necessidades futuras, o aumento da competitividade do governo e o fomento de uma cultura de autodesenvolvimento contínuo.

No Brasil, o Governo Federal, pelo menos no âmbito do poder executivo, introduziu a gestão por competências por intermédio da ediçấo do Decreto No 5.707/06 (BRASIL, 2006), que instaura a Política Nacional de Desenvolvimento de Pessoal (PNDP) para os órgãos da administração direta, autárquica e fundacional. Apesar de o citado decreto prever o alinhamento das competências individuais e institucionais, as características específicas do contexto institucional da administração pública ensejam investigações sobre a transposição para organizaçôes públicas desse modelo de gestão surgido no âmbito de empresas orientadas para uma lógica de competitividade de mercado. É neste cenário que autores como Lacombe e Chu (2008) e Apel e Bitencourt (2008) reconhecem a necessidade de se avaliar o ambiente institucional e sua propensão à implantação de um modelo baseado em competências. As características ambientais e organizacionais podem condicionar a autonomia de gestores para implantação de mudanças organizacionais (FONSECA et al., 2013; PAAUWE; BOSELIE, 2003). Consequentemente, há condicionantes para a trajetória de institucionalização da gestão por competências no setor público, conduzida em um processo gradual de desenvolvimento e difusão do modelo no setor público, conforme suas necessidades e exigências sociais, organizacionais e institucionais específicas.

Portanto, o presente estudo expóe os resultados de um processo de análise da implantação do modelo de gestáo por competências e suas perspectivas de desenvolvimento no âmbito das agências reguladoras federais. Especificamente, a pesquisa visou identificar os fatores que afetam positiva e negativamente a implantação da gestáo por competências 
nesse âmbito. Sobretudo buscou-se a aplicação de pressupostos da teoria institucional na perspectiva prática do processo de institucionalização desse modelo, por meio da percepçáo dos gestores se servidores implicados no processo.

Justifica-se a pesquisa proposta em função da renovada relevância do tema, aliada às reflexôes que tem suscitado entre gestores e servidores públicos, que tornam a gestão estratégica de pessoas no setor público brasileiro um campo com crescente necessidade de consolidaçáo por meio de uma agenda de investigação consistente e específica (FONSECA et al., 2013). Da mesma forma, a pesquisa visa contribuir para a análise de elementos institucionais presentes na reforma da Administraçẫo Pública, sempre notada como de grande necessidade para o aperfeiçoamento da qualidade dos serviços públicos e da competitividade do país.

\section{A GESTÁO DE PESSOAS POR COMPETÊNCIAS}

Durante a década de 1980, a maior competitividade dos mercados internacionais suscitou o surgimento de teorias organizacionais voltadas para a melhoria da performance das empresas no mercado. Neste período, surgiu a principal teoria sobre a qual se assentam os modelos estratégicos de recursos humanos - a Visão Baseada em Recursos (VBR) - segundo a qual o desempenho de uma organização dependeria da focalização no uso efetivo de seus recursos internos em estratégias bem definidas e sustentadas na capacidade de agregação de valor para o mercado de forma diferenciada (PAAUWE; BOSELIE, 2003). Esse diferencial competitivo, sob a forma de tecnologias, métodos e práticas empresariais, foi denominado, por Prahalad e Hamel (1990), como competências essenciais da organização, cuja consolidação dependeria do arranjo e da qualidade dos recursos internos da empresa, dentre os quais os seus recursos humanos (WRIGHT; MCMAHAN, 1992).

O modelo de gestão por competências se insere no contexto da gestáo estratégica, dado que se caracteriza pela capacidade de alinhamento horizontal, das atividades de gestáo de pessoas, e vertical, dessas atividades com a estratégia da organização (ORGANIZAÇÃO PARA A COOPERAÇÁO E DESENVOLVIMENTO ECONÔMICO, 2010b). O constructo teórico "competência" é descrito na literatura em diferentes níveis: organizacional (PRAHALAD;
HAMEL, 1990), coletivo e individual, que integra o requisito de atributos cognitivos e comportamentais para o desempenho do trabalho na organização (BRANDÁO; GUIMARÃES, 2001). A competência ao nível do indivíduo permite a conexão entre os diferentes sistemas de gestão de pessoas, em função de uma linguagem comum, de forma que as atividades se estruturam de forma integrada às competências, como por exemplo: o dimensionamento da força de trabalho; o recrutamento e a seleção; treinamento e desenvolvimento; a gestáo do desempenho e da remuneração; e o planejamento de carreiras (ORGANIZAÇÃO PARA A COOPERAÇÃO E DESENVOLVIMENTO ECONÔMICO, 2010b). Nessa perspectiva, o mapeamento de competências identificará as lacunas entre as competências requeridas e aquelas já disponíveis na organização de forma a orientar a atuação dos sistemas de gestáo de pessoas para que atuem coordenadamente em torno da captação e desenvolvimento de competências para preenchimento das lacunas identificadas (BRANDÁO; BARHY, 2005).

A literatura referente à gestáo por competências, por muito tempo apresentou teorias e modelos desvinculados do contexto de aplicação, tendo um caráter universalista e genérico (CAPALDO; IANDOLI; ZOLLO, 2006), o que, na realidade, reflete uma lacuna teórica da própria literatura de gestão estratégica de pessoas (JACKSON; SCHULER; JIANG, 2014). A gestão por competências, tendo em vista sua origem no setor privado britânico e norte-americano (ORGANIZAÇÃO PARA A COOPERAÇÃO E DESENVOLVIMENTO ECONÔMICO, 2010b), tem suscitado questóes acerca da sua adaptação ao contexto brasileiro (APEL; BITENCOURT, 2008) e ao contexto específico do setor público (ORGANIZAÇÃO PARA A COOPERAÇÃO E DESENVOLVIMENTO ECONÔMICO, 2010b).

Os fatores de sucesso para a implantação da gestão por competências têm sido descritos de maneira pouco aprofundada e genérica, como uma teoria universalista (PAAUWE; BOSELIE, 2003). Enumeram-se fatores predominantemente organizacionais, tais como a necessidade de participação ativa dos gestores e funcionários, a construção coletiva de competências, a coerência do seu alinhamento estratégico, horizontal e com a realidade de trabalho e cultura organizacionais (ORGANIZAÇÃO PARA A COOPERAÇÁO E DESENVOLVIMENTO ECONÔMICO, 2010b). Sendo assim, por um lado, a 
concepção da gestão por competências reflete princípios da linha teórica da Visão Baseada em Recursos, segundo a qual a organização deve se basear em seus recursos e competências internas para determinação de sua estratégia, e desenvolvendo modelos gerenciais próprios, de forma competitiva e alinhada à sua cultura e processos de trabalho (PAAUWE; BOSELIE, 2003; BRANDÃO; GUIMARÃES, 2001; CAPALDO; IANDOLI; ZOLLO, 2006). Por outro lado, não há um aprofundamento de aspectos institucionais e estruturais do ambiente organizacional que condicionam a implementação desse modelo (APEL; BITENCOURT, 2008; PAAUWE; BOSELIE, 2003), sobretudo no setor público (FONSECA et al., 2013). O ambiente institucional e a atuação do Governo, por meio de órgãos centrais, estabelecem diretrizes e dispositivos legais que terminam por vincular as estratégias adotadas nos demais órgãos públicos (BACH, 2010). O Governo também é responsável pela política de gestão de pessoas, em termos globais, limitando a autonomia das organizaçóes públicas no desenvolvimento de seus próprios modelos e formas de integração de práticas de gestão (FONSECA et al., 2013). Logo, a concepção da gestão por competências no contexto do setor público requer, do ponto de vista analítico, complementação teórica para uma análise que considere as variáveis externas à organização, que influenciam os modelos de gestáo adotados.

\subsection{A Gestáo por Competências e o Novo Institucionalismo}

A Visão Baseada em Recursos, aplicada aos sistemas vigentes de gestão de pessoas, confere às competências destaque central como recursos estratégicos dos quais depende a organizaçáo para a consecução de seus objetivos. Baseia-se, assim, na suposição de racionalidade dos gestores para condução de políticas de recursos humanos adequadas à estratégia corporativa. No entanto, Lacombe e Chu (2008) estabelecem, a partir de Paauwe e Boselie (2003), certos limites para essa racionalidade. Para ambos os grupos de autores, muitas das decisões gerenciais no âmbito da organização são tomadas de forma parcialmente racional, quando consideradas pressôes do ambiente como determinantes das práticas de gestão de pessoas.

A administração pública se caracteriza por um ambiente normatizado, onde a mudança organizacional se opera dentro de aspectos legais restritivos e do contexto sócio-político no qual se insere como agente representativo (BACH, 2010). Logo, a gestão de pes- soas em órgãos públicos é parcialmente determinada pela influência de fatores institucionais diversos, exercida por meio dos demais órgãos da administraçáo, sindicatos, associaçóes profissionais, universidades, empresas de consultorias etc. (LACOMBE; CHU, 2008). Estudos da OCDE (2010a), por exemplo, indicam que o ambiente legal brasileiro e a cultura funcional do serviço público têm dificultado a implementação desse modelo, embora esta seja a soluçáo recomendada para as distorçôes e disfunçôes da atual política de gestão de pessoas. Sob essa perspectiva, pode-se considerar que a implantação da gestão por competências, depende não só de fatores organizacionais, mas de um ambiente institucional favorável para se efetivar.

Recorre-se, assim, ao Novo Institucionalismo, preconizado por DiMaggio e Powell (1991), cujas bases assentam-se em uma perspectiva de análise das organizações do ponto de vista de sua conformação ao ambiente institucional. Para tais autores, as organizações tendem a aderir aos padróes de seu setor e da sociedade em uma perspectiva de legitimação identitária, a qual pode refletir-se no assemelhamento de práticas gerenciais (DIMAGGIO; POWELL, 1991). Denominado de isomorfismo, este processo se caracteriza, de modo geral, pela pressão no sentido de uma conformidade de práticas entre empresas, um processo restritivo que leva a organizaçáo a adotar estruturas e processos semelhantes às demais em seu ambiente (LACOMBE; CHU, 2008). Porter (1980), em sua abordagem competitiva para as organizaçôes, também prevê esta tendência isomórfica, porém a compreende como uma tentativa da organização de neutralizar inovaçóes e vantagens de competidores que a ameaçam no mercado. Para se tornar mais competitiva, a organização deve possuir estratégias de diferenciação de difícil reprodução pelos concorrentes.

Paauwe e Boselie (2003) distinguem, portanto, duas formas de isomorfismo: competitivo e institucional. $\mathrm{O}$ primeiro se refere à mencionada abordagem porteriana, relativa às pressóes $\mathrm{da}$ indústria e decisóes racionais de posicionamento estratégico, sendo mais relevante quando a competição é livre e aberta. O segundo se refere às mudanças por fatores ambientais sociais, legais e simbólicos, em uma perspectiva mais profunda que não necessariamente se fundamenta em critérios racionais. Dessa forma, embora não seja adequado presumir que o conceito de competitividade é incompatível com organizações de Governo, a influência do ambiente de mercado é relativizada no 
setor público, onde se afiguram outros determinantes para a sua estratégia. O Estado atua em função de sua representatividade sócio-política e suas instituiçōes devem, portanto, corresponder, na prática, aos valores vigentes para legitimarem-se perante a sociedade. Pressupôe-se, assim, que órgãos da administração pública possuem ampla representatividade social e guardam um elevado grau de e semelhança entre si, o que favorece a ocorrência do isomorfismo institucional.

\subsection{Tipos de Isomorfismo}

DiMaggio e Powell (1991) determinam três tipos de isomorfismo institucional: coercitivo, normativo e mimético (Figura 1). Segundo os autores, o isomorfismo coercitivo ocorre por meio da imposição (formal e informal) sofrida pela organização por outra, da qual depende. Nesse caso, as açōes e transformações ocorrem por imposição e força de autoridade, como é o caso da submissão às leis do governo ou à pressão de sindicatos. Já o isomorfismo mimético diz respeito à adoção, pela organização-alvo, das práticas engendradas por outras em seu setor; à busca das melhores soluçôes - benchmarking - como forma de compensar a falta de recursos para desenvolvimento de iniciativas próprias. Por fim, o isomorfismo normativo decorreria da homogeneidade de práticas profissionais do mercado refletidas em uma uniformidade de práticas dentro das empresas. Este papel é desempenhado, principalmente, pelas universidades, como formadoras de conhecimentos que se difundem no mercado por intermédio de seus profissionais.

\subsection{O Processo de Institucionalizaçáo}

Os fatores relacionados a cada tipo de isomorfismo demonstram os tipos de influência que instituiçóes externas à organização podem legar aos seus processos internos. A concepção da institucionalização é definida por Tolbert e Zucker (1999) como a tipifi- cação de açôes organizacionais tornadas habituais por atores específicos e que adquirem valor social próprio, prevalecendo ao longo do tempo. No entanto, as autoras reconhecem que o conceito de institucionalização, como qualidade atribuída às estruturas, é limitado para fins de análise organizacional. Dessa forma, após demonstrarem a necessidade de compreensão do fenômeno sob uma perspectiva processual de análise, e não simplesmente como evento de natureza episódica, propóem um modelo de três estágios para a institucionalização de uma estrutura, como forma de compreensão dos seus fatores determinantes.

O primeiro estágio denomina-se, então, de habitualização e envolve o início da adoção de novas políticas desenvolvidas para a resolução de problemas. Essas políticas se encontram formalizadas e são implementadas experimentalmente em uma etapa pré-institucional, na qual o novo modelo é conhecido e avaliado para, entâo, tender a se difundir entre organizações extremamente similares (APEL; BITENCOURT, 2008; TOLBERT; ZUCKER, 1999). Por decorrer de um processo decisório, há grande sensibilidade ao arranjo político organizacional, o qual avalia e formaliza a implantação da inovação principalmente sob o critério do acréscimo de valor para a organização. Neste estágio é comum que haja uma diversidade de métodos de implantaçáo e formatos da nova estrutura, tendo em vista a construção e a adaptação próprias realizadas pelas organizaçóes. Verifica-se, também, um alto grau de fracasso, dado o caráter experimental da inovação e a sua baixa consistência na coexistência com as estruturas já estabelecidas na organização.

O estágio seguinte, de objetificação, se dá por meio da existência de consenso entre os decisores organizacionais sobre o valor da inovaçáo e, consequentemente, da sua transformação em um tema difundido no mercado, caracterizando o interesse de outras organizaçóes e de estudiosos em buscar uma

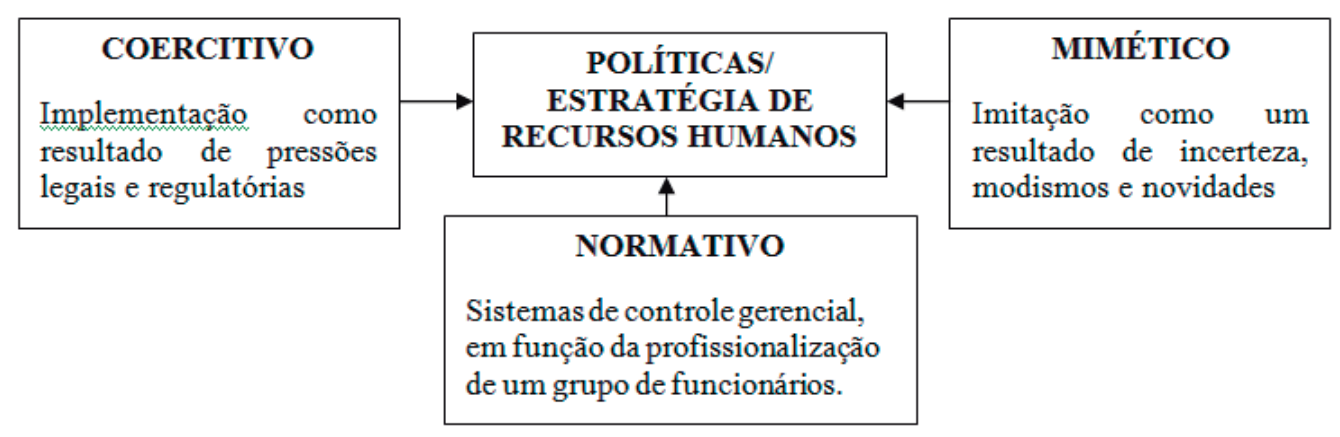

Figura 1 - Tipos de isomorfismos atuantes na definição de políticas de recursos humanos Fonte: Adaptado de Paauwe e Boselie (2003, p. 61) 
Tabela 1. Pilares das Teorias Institucionais. (Fonte: Apel e Bitencourt 2008, p. 179)

\begin{tabular}{cccl}
\hline Pilar & Pressuposto & Isomorfismo & \multicolumn{1}{c}{ Lógica } \\
\hline Regulativo & Realista social & Coercitivo & $\begin{array}{l}\text { Normas, leis e sanções constituem a base da } \\
\text { legitimação institucional. }\end{array}$ \\
Normativo & Conformidade & Mimético & $\begin{array}{l}\text { Dimensão moral fundamentada no contexto } \\
\text { social. }\end{array}$ \\
Cognitivo & $\begin{array}{l}\text { Social } \\
\text { construcionismo }\end{array}$ & Normativo & $\begin{array}{l}\text { Fundamentada na noção de } \\
\text { compartilhamento, de comulidade de } \\
\text { conhecimentos culturalmente difundidos e } \\
\text { socialmente aceitos. }\end{array}$ \\
\hline
\end{tabular}

consolidação teórica com respaldo social. A difusão da estrutura gera uma crescente pressão isomórfica ambiental e se expressa na criação de grupos de apoio que desempenham um papel de liderança na implantaçẫo de um projeto ou alcance de um objetivo. Tais grupos são comumente associados a grupos de poder ou consultores que visam à consolidação de um produto para criação de um mercado, contribuindo para a institucionalização da inovação (TOLBERT; ZUCKER, 1999).

Por fim, a etapa de sedimentação se refere à institucionalização total que se afigura na legitimidade da estrutura e sua perpetuação no tempo. A partir de entáo, o novo modelo será incorporado culturalmente e defendido pelos gestores que evitaráo a desinstitucionalização da prática. Para tal, é necessária a atuação permanente de grupos de apoio, prevalecentes na etapa anterior, a fim de se manter um baixo nível de oposição à nova estrutura e, consequentemente, a inibiçâo da percepção de alternativas mais eficazes à geraçáo de resultados positivos para as pessoas e as organizaçóes (APPEL; BITENCOURT, 2008; TOLBERT; ZUCKER, 1999).

Além dessas etapas, é importante destacar, para fins de interpretaçáo dos resultados da pesquisa sob análise, que este processo de institucionalização pode ainda ser avaliado sob três dimensões (SCOTT, 1994 apud APEL; BITENCOURT, 2008), representadas pelos aspectos regulativos, normativos e cognitivos da mudança (Tabela 1).

O aspecto cognitivo representa a dimensão social da mudança, a sua aceitação por parte dos gestores e usuários que sofrem diretamente os seus impactos. A dimensão normativa se refere à validação geral do modelo, consolidado e socialmente aceito. Em seguida, a dimensão regulativa normatiza essa prática sob a forma de leis e regulamentos. A consolidação na dimensão cognitiva, expressa na construção social, como pressuposto para institucionalização, relati- viza o caráter determinista, normalmente atribuído ao isomorfismo, pois denota que os indivíduos não são passivos, pois atuam na atribuição de significado à mudança (SCHOMMER, 2003). Nesta perspectiva, a nova estrutura sofre adaptaçóes conforme os interesses dos atores, construídos e difundidos na organização. Logo, a institucionalização, de maneira natural, se daria com o desenvolvimento de práticas a partir da construção social, sob o pilar cognitivo, que se projetaria gradualmente nos pilares normativo e regulativo em direção à conformidade social.

\section{MÉTODO DE PESQUISA}

A presente pesquisa, observacional de campo, classifica-se como descritiva, quanto aos seus fins, pois objetivou expor o estágio atual (corte transversal) do processo de implantação da gestáo por competências em agências reguladoras no dado cenário normativo e institucional do Governo Federal. Sua abordagem se deu pela aplicação de um levantamento qualitativo, por meio de entrevistas semiestruturadas com servidores lotados nas unidades de recursos humanos de cada uma das agências reguladoras atuantes no Brasil. A função essencial das agências reguladoras consiste em assegurar o atendimento do interesse público na prestação de serviços nos setores econômicos cedidos por contrato à exploração por concessionários, autorizatários e permissionários da iniciativa privada.

\subsection{Populaçáo e Amostra}

A amostragem das organizaçóes foi de natureza censitária, tendo sido abordadas todas as dez agências reguladoras atuantes no Brasil. A Tabela 2 expõe informaçôes básicas das agências participantes da pesquisa.

Acerca da composição desta população, as agências reguladoras federais foram escolhidas por possuírem semelhanças quanto ao ambiente normativo, 
Tabela 2. Agências Reguladoras Federais. (Fonte: Gelis Filho 2006, p. 600)

\begin{tabular}{|c|c|c|}
\hline Denominação & Lei de criação & Atividades reguladas \\
\hline $\begin{array}{l}\text { Agência Nacional de Energia Elétrica - } \\
\text { ANEEL }\end{array}$ & $\begin{array}{l}\text { Lei n. } 9.427 \text {, de } \\
\text { 26/12/1996 }\end{array}$ & $\begin{array}{l}\text { Produção, transmissão, } \\
\text { distribuição e comercialização de } \\
\text { energia elétrica }\end{array}$ \\
\hline $\begin{array}{l}\text { Agência Nacional de } \\
\text { Telecomunicações - ANATEL }\end{array}$ & $\begin{array}{c}\text { Lei n. } 9.472 \text {, de } \\
16 / 07 / 1997 \\
\end{array}$ & Telecomunicações \\
\hline Agência Nacional de Águas - ANA & $\begin{array}{c}\text { Lei n. 9.984, de } \\
17 / 07 / 2000 \\
\end{array}$ & Recursos hídricos \\
\hline $\begin{array}{l}\text { Agência Nacional de Vigilância } \\
\text { Sanitária - ANVISA }\end{array}$ & $\begin{array}{l}\text { Lei n. } 9.782 \text {, de } \\
\text { 26/01/1999 }\end{array}$ & $\begin{array}{l}\text { Produção e comercialização de } \\
\text { produtos e serviços submetidos à } \\
\text { vigilância sanitária }\end{array}$ \\
\hline $\begin{array}{l}\text { Agência Nacional de Saúde } \\
\text { Suplementar - ANS }\end{array}$ & $\begin{array}{l}\text { Lei n. } 9.961 \text {, de } \\
28 / 01 / 2000\end{array}$ & Assistência suplementar à saúde \\
\hline $\begin{array}{l}\text { Agência Nacional do Petróleo, Gás } \\
\text { Natural e Biocombustíveis - ANP }\end{array}$ & $\begin{array}{c}\text { Lei n. } 9.478 \text {, de } \\
06 / 08 / 1997\end{array}$ & Indústria do petróleo \\
\hline $\begin{array}{l}\text { Agência Nacional de Transportes } \\
\text { Aquaviários - ANTAQ }\end{array}$ & $\begin{array}{l}\text { Lei n. } 10.233 \text {, de } \\
05 / 06 / 2001\end{array}$ & $\begin{array}{l}\text { Infraestrutura de transportes } \\
\text { aquaviários }\end{array}$ \\
\hline $\begin{array}{l}\text { Agência Nacional de Transportes } \\
\text { Terrestres - ANTT }\end{array}$ & $\begin{array}{l}\text { Lei n. 10.233, de } \\
05 / 06 / 2001\end{array}$ & $\begin{array}{l}\text { Infraestrutura de transportes } \\
\text { terrestres }\end{array}$ \\
\hline $\begin{array}{l}\text { Agência Nacional do Cinema - } \\
\text { ANCINE }\end{array}$ & $\begin{array}{c}\text { Medida Provisória } \\
\text { n. } 2.228-1, \text { de } \\
06 / 09 / 2001 \\
\end{array}$ & $\begin{array}{l}\text { Indústria cinematográfica e } \\
\text { videofonográfica }\end{array}$ \\
\hline $\begin{array}{l}\text { Agência Nacional de Aviação Civil - } \\
\text { ANAC }\end{array}$ & $\begin{array}{l}\text { Lei n. } 11.182 \text {, de } \\
\text { 27/09/2005. }\end{array}$ & $\begin{array}{l}\text { Infraestrutura aeronáutica, } \\
\text { aeroportuária e sistema de } \\
\text { aviação civil }\end{array}$ \\
\hline
\end{tabular}

especificamente no que se refere à legislação sobre gestão de pessoas, tendo em vista a carreira dos servidores destes órgãos, definida na Lei No 10.871/04, ser comum a todas as agências. A abordagem da totalidade desse universo permitiu atenuar fatores organizacionais particulares e evidenciar características e impressões comuns no âmbito do setor de regulação.

A seleção dos participantes em cada agência compôs uma amostra intencional, a qual adotou como critério o envolvimento formal do servidor com a implantação da gestão por competências em seu órgão. Esse critério justifica-se pela busca de informaçôes relativas ao histórico de implantação do modelo no órgão e a perspectiva dos agentes neste processo. Desta forma, participaram do estudo, um total de 18 servidores públicos, entre os quais dois gerentes gerais de gestão de pessoas, oito coordenadores da área de capacitaçáo e/ou gestáo por competências, sete funcionários atuantes na área de capacitação e uma funcionária atuante na gerência geral de gestão de pessoas. Quanto aos cargos dos participantes, foram entrevistados quatro Gerentes Executivos, 12 Analistas Administrativos e dois Técnicos Administrativos. As áreas de formação predominantes são Administração, Psicologia e Pedagogia.

\subsection{Instrumento}

$\mathrm{O}$ instrumento de pesquisa utilizado constituiuse de um roteiro de entrevista composto por sete questóes orientadas para obtenção dos dados relativos aos objetivos da pesquisa e pressupostos da literatura. A primeira questáo solicita ao participante que discorra sobre as adequaçóes que passaram a ocorrer na agência em função do Decreto N.o 5.707/06, com o objetivo de se obter acesso ao histórico de iniciativas do órgão, dificuldades e fatores implicados e, por fim, qual a situação final do processo, ou seja, o grau de implantação do modelo.

As questóes de $\mathrm{n}^{\circ} 2$ a 5 buscam aprofundar a narrativa inicial evidenciando os fatores específicos que afetaram o processo de implantação do modelo. Questionam-se quais ações de implantação foram consideradas bem sucedidas (questão $\mathrm{n}^{\circ} 2$ ), quais não tiveram sucesso (questâo no 3 ) e quais facilitadores e dificuldades do processo para o órgão. A questấo de no 4 foi feita somente às agências que afirmaram possuir práticas baseadas em competências, sendo questionado em que aspectos as novas práticas diferenciam-se das anteriores. A questáo de $n^{\circ} 5$ se atém ao aspecto da presença dos gestores no processo, tendo em vista tratar-se de um fator relevante apontado pela literatura (ORGANIZAÇÃO PARA A COOPERAÇÃO E 


\section{DESENVOLVIMENTO ECONÔMICO, 2010b).}

A questấo de no 6 insere a previsão teórica do alinhamento horizontal e busca a impressão dos participantes com relação à viabilidade de aplicação do modelo de gestão por competências na capacitação, e nos demais subsistemas de gestão de pessoas. A questão visa detectar a existência, nas agências, de aplicação do modelo por competências em outros subsistemas e de se obter uma análise do contexto da administraçấo pública e perspectivas de implantação de um modelo integrado de gestão de pessoas por competências.

O objetivo da última questão, de no 7 , é de resgatar a narrativa por completo ao solicitar ao participante que defina precisamente quais fatores e aspectos, levantados por ele próprio nas questôes anteriores, são mais relevantes para a implantação da gestão por competências. A questão busca, portanto, destacar, dentre os diversos fatores existentes no processo, aqueles considerados críticos pelos participantes.

\subsection{Coleta e Análise dos Dados}

Para coleta dos dados foi submetida correspondência eletrônica aos órgáos com apresentação da pesquisa e, posteriormente, agendadas entrevistas com as pessoas indicadas. Seis entrevistas se deram de forma presencial, nos locais de trabalho dos participantes, e quatro se deram de forma remota, por intermédio de contato telefônico em rede de dados. As entrevistas foram gravadas em sua integridade para posterior transcrição. Dentre as entrevistas presenciais, quatro ocorreram com duplas de participantes, uma com cinco e uma com apenas um participante. As entrevistas remotas contaram com apenas um participante cada. O número de participantes foi determinado pelos próprios entrevistados conforme critérios da amostra intencional.

Para a análise dos dados, primeiramente foi empregada a transcrição integral das entrevistas de forma literal, com base na metodologia preconizada por Bardin (2009). Posteriormente, sobre as transcriçōes, foi utilizada a análise de conteúdo, que identifica os temas emergentes no discurso e o que foi dito a respeito daqueles temas (VERGARA 2006). Como sugere Vergara (2006), a identificação dos fatores obedeceu a uma categorização em uma grade aberta, que identifica as categorias de análise conforme estas surgem na pesquisa. Os fatores inclusos nessas categorias foram considerados conforme a sua importância e significação para a temática da pesquisa e sistematizados como unidades de registro, ou recortes de teor significativo e semântico para fins de categorização e contagem de frequência (BARDIN, 2009).

\section{RESULTADOS}

Atualmente, as agências reguladoras se encontram em diferentes estágios de implantação do modelo de gestáo por competências. Conforme observaram alguns entrevistados, as agências divergem quanto aos patamares de desenvolvimento, estruturas organizacionais e de pessoal, cultura, estilos de gestáo e diversos outros aspectos que culminam na determinação de diferentes capacidades de implantação do modelo e na geração de diferentes resultados frente ao fator comum da edição do Decreto N.o 5.707/06.

Nesse sentido, foram detectadas interrupçóes na implantação em quatro agências, decorrentes de fatores como o baixo apoio interno, a alteração constante da estrutura organizacional e a incapacidade de adequação de processos de trabalho, entre outros. Conforme relatos abaixo, se verificam alguns pressupostos percebidos pelos entrevistados para sucesso do mapeamento de competências:

\footnotetext{
"[...] é com base na documentação que a gente tem, atualizada, e no planejamento estratégico da instituição que a gente pode começar a fazer esse trabalho de mapeamento" (Analista, Agência 2)

“...ele [o primeiro mapeamento] foi totalmente interrompido e a gente teve uma mudança de $100 \%$ no quadro, entâo ele literalmente recomeçou do zero" (Coordenador, Agência 5)
}

Em funçáo de muitas agências estarem atualmente realizando reestruturaçóes, suprindo seus quadros de servidores e definindo seus planejamentos estratégicos, o processo de implantação do modelo tem sido, em geral, postergado. Posterior a essa estruturação interna haveria o processo de elaboração e aplicação do mapeamento de competências, o qual durou cerca de cinco meses nas agências que concluíram o processo.

Foram identificadas apenas duas agências que concluíram o mapeamento de competências e buscam aplicar práticas de gestáo de pessoas baseadas em competências, sendo apenas nos subsistemas de capacitação e de avaliação de desempenho (Agências 1 e 5). Tal aplicação consistia fundamentalmente na utilizaçấo das competências como critério para o planejamento e a oferta de capacitação para servidores, 
baseando-se em áreas de conhecimento associadas. Nas avaliaçốes de desempenho, as competências descreveriam os comportamentos esperados dos servidores, cuja expressão no contexto de trabalho seria avaliada pelas chefias, de forma complementar aos critérios de desempenho tradicionalmente prescritos pela legislação.

Com relaçấo ao restante da amostra, parte das agências estava em processo de realização do mapeamento de competências (Agências 3, 9 e 10) e a sua maioria ainda perpassava por estruturações sem ter iniciado o seu mapeamento (Agências 2, 4, 6, 7 e 8). Logo, tendo em vista os pressupostos da gestáo por competências como uma gestáo integrada de subsistemas, nenhum dos órgãos analisados possui um modelo consolidado.

Ao se considerar os aspectos definidos no estágio de pré-institucionalização, ou habitualização, por Tolbert e Zucker (1999), verifica-se nas agências: a heterogeneidade de modelos, adaptados conforme os recursos e necessidades organizacionais; a susceptibilidade ao arranjo político interno; e a ocorrência de interrupções e fracassos. Esses aspectos sugerem a caracterização da gestáo por competências como em estágio pré-institucional no Governo. Isto não implica na inexistência de fatores relativos aos demais estágios, visto que, apesar da proposição sequencial dos autores supracitados, as características de cada es- tágio permeiam e se consolidam por todo o processo de institucionalização de forma dinâmica (MACHADO-DA-SILVA; GONGALVES, 1999).

Desta forma, foram identificados nas falas dos entrevistados 19 diferentes fatores, relativos ao processo de institucionalização, associados aos pressupostos da gestão estratégica de pessoas e da Teoria Institucional. A análise do conteúdo das entrevistas permitiu a classificação desses fatores em seis categorias gerais abrangentes aos seguintes assuntos: Normativo-Legais, Políticos, Organizacionais, Técnico-Metodológicos, Culturais e Recursos Humanos. Dentro dessas categorias foram classificadas as unidades temáticas, relativas aos fatores específicos identificados que interferem na implantação do modelo.

$\mathrm{Na}$ Tabela 3, cujo propósito consiste em expor tal categorização, a ocorrência dos fatores está representada por meio do valor de sua "presença", sendo essa uma medida de sua ocorrência no número determinado de agências, demonstrando o seu grau de predominância no setor, podendo variar entre uma e dez agências, que afirmaram a sua ocorrência. Da mesma forma, demonstrou-se por meio do valor de "presença crítica” o número de agências que destacaram, dentre os demais fatores, aquele considerados especificamente essenciais para o processo de implantação do modelo, podendo variar igualmente, entre uma e dez agências que consideram o fator como crítico em relação

Tabela 3. Categorização dos resultados de pesquisa.

\begin{tabular}{clcc}
\hline Categorias & \multicolumn{1}{c}{ Fatores } & Presença & Presença crítica \\
\hline \multirow{2}{*}{ Normativo-Legal } & Legislação & 9 & 3 \\
& Coerção normativa & 4 & - \\
\hline \multirow{2}{*}{ Políticos } & Apoio da cúpula & 7 & 6 \\
& Rotatividade de Gestores & 5 & 2 \\
\hline \multirow{5}{*}{ Organizacionaiis } & Estrutura do quadro de servidores & 3 & 2 \\
& Solução prática de necessidades organizacionais & 4 & - \\
& Existência de Planejamento Estratégico & 10 & 2 \\
& Estrutura Organizacional & 6 & 1 \\
& Mapeamento de Processos Organizacionais & 3 & 1 \\
& Integração com outras organizações & 3 & 1 \\
\hline \multirow{2}{*}{ Técnico- } & Metodologia Utilizada & 9 & 1 \\
Metodológicos & Orientação e acompanhamento do Governo & 8 & 6 \\
& Suporte de sistema de gestão & 6 & 4 \\
\hline \multirow{2}{*}{ Culturais } & Sensibilização dos gestores e servidores & 9 & 4 \\
& Grupos de Resistência & 4 & - \\
& Expectativa de Resultados & 8 & 6 \\
\hline Recursos & Capacitação e domínio técnico & 9 & 4 \\
Humanos do & Mobilização do setor de gestão de pessoas & 4 & - \\
Projeto & Tamanho da equipe de trabalho & 8 & 6 \\
\hline
\end{tabular}


aos demais. Essa diferenciação entre os dois valores (presença e presença crítica) buscou distinguir entre a simples predominância do fator e a sua relevância, uma vez que a última visa identificar os fatores de maior influência no âmbito das agências, que podem ser gargalos ou pontos condicionantes para o processo de institucionalização da gestão por competências.

É possível observar a abrangência das categorias analíticas em diferentes aspectos do processo de implantação e níveis de análise, demonstrando o caráter sistêmico do processo e a presença empírica de diversos fatores apontados na literatura. Evidenciam-se também aspectos técnicos da gestão por competências no contexto brasileiro. Dessa forma, em seguida, a análise de cada uma dessas categorias é desenvolvida sob a ótica de tal enquadramento teórico com exemplificação de trechos das entrevistas.

\subsection{Fatores Normativo-Legais}

A categoria de fatores normativo-legais se refere à influência do ambiente normativo do Governo e de normas infralegais. No estudo, foi relatada a motivaçáo extrínseca para implantaçáo do modelo como adequaçáo ao Decreto N. ${ }^{\circ}$ 5.707/06, denotando a prevalência do isomorfismo coercitivo (DIMAGGIO; POWELL, 1999), conforme esperado da estrutura centralizada do Governo e do ambiente institucional brasileiro (APPEL; BITENCOURT, 2008; MACHADO-DA-SILVA; GONÇALVES, 1999). Essa inversão do processo natural de institucionalização (APEL; BITENCOURT, 2008) favorece a limitação da racionalidade dos atores em função das pressōes ambientais (PAAUWE; BOSELIE, 2003). Neste caso, a restrição coercitiva está expressa nos fatores Legislação e Coerção Normativa.

O fator Legislação denota a contribuição da estrutura legal para a institucionalização da gestão por competências. Relatou-se que a legislação de gestão de pessoas é extremamente fragmentada, havendo uma divisão dos subsistemas em diferentes dispositivos legais, os quais não estấo integrados entre si, e atuam isoladamente, com foco no controle do servidor.

"As políticas que saem não são, muitas vezes, casadas [...] Então eu tenho políticas que na concepção delas, já não são integradas” (Coordenador, Agência 5)

"[Tem que] Rever toda a política de Recursos Humanos do Governo, para que isso migre para a gestão por competências, porque hoje você tem várias Leis e Decretos que fazem uma mistura enorme.[...] É incoerente." (Gerente, Agência 4) "[Há] uma falta de integraçáo das normas [...] às vezes cada uma diz uma coisa. Elas não estão alinhadas. [...] Não tem uma, digamos assim, orientação estratégica para a gestão de pessoas» (Analista, Agência 10)

A falta de integração de subsistemas, expressa na legislação, evidencia as características, apontadas por Wright e McMahan (1992), de um modelo estratégico de gestão de pessoas ainda incompleto, no qual as práticas são concebidas estrategicamente, porém de forma isolada, sem o desenvolvimento de técnicas efetivas de integração horizontal. A especificaçáo no Decreto N. ${ }^{o} 5.707 / 06$ de uso da gestão por competências como instrumento de capacitaçấo estratégica, não leva em consideração que esta não se efetiva sem a integração com os demais subsistemas.

Outro aspecto legal apontado nas entrevistas, no caso do referido Decreto, é a generalidade de sua redação, tida como ambígua, passível, de múltiplas interpretaçôes e, consequentemente, de diferentes formas de implantação. Evidenciam-se, portanto, três aspectos inibidores da institucionalização da gestão por competências no que tange ao fator Legislação: (a) fragmentação normativa; (b) teor burocrático com foco no controle; (c) ambiguidade. Depreendese, portanto, que os aspectos da Legislação de pessoal que contribuem para a institucionalização seriam (a) a sua integraçáo e consistência normativa; (b) compatibilidade com princípios gerenciais focados em resultados, e (c) a redação concisa e específica na definição de conceitos.

O fator Coerção Normativa pode ser compreendido como um aspecto da legislação, porém, nesse estudo, em quatro agências foi apontado também como necessário em dispositivos infralegais como contratos de gestâo e planos estratégicos. Esses dispositivos fixam metas formais e prazos para implantação do modelo, de forma que se observou a aceleraçáo da sua institucionalização nas agências sujeitas a uma pressão institucional maior, geralmente exercida por órgãos dos quais depende ou possui relação de subordinação. Não obstante a autonomia administrativa das agências, alguns dispositivos de avaliaçấo de desempenho institucional permitem certo grau de coerção sobre essas, na medida em que procuram suprir suas metas de desempenho para assegurar legitimidade e acesso a recursos (DIMAGGIO; POWELL, 1990). 
Esse fator é especialmente relevante no Governo, onde a administração central possui uma relação de poder com os demais órgáos, tanto como o monopólio e discricionariedade sobre os recursos públicos. Assim, um aumento na coerção, ou grau de ameaça à sobrevivência institucional, na visão dos atores, pode ser tido como um fator para a adoção mais célere de inovaçôes. Corrobora esse fator estudo de Silva e Godoi (2006), no qual a implantação da gestão por competências em uma empresa pública foi bem sucedida após ser fixada como meta em contrato de gestáo com o Governo, sob risco de sua privatização, portanto, uma ameaça externa aos funcionários e gestores.

\subsection{Fatores Políticos}

Os mecanismos de pressão institucional identificados no isomorfismo coercitivo, no presente caso, indicam como será interpretada a necessidade de inovação pelos dirigentes das organizaçóes (MACHADO-DA-SILVA; GONÇALVES, 1999; TOLBERT; ZUCKER, 1999). Observou-se que, nos casos em que houve um alto grau de coerção, menor foi a discricionariedade dos gestores (PAAUWE; BOSELIE; 2001). Porém, na maioria das agências, a implantação foi resultado de um processo decisório baseado no consenso sobre a utilidade e oportunidade da inovação conforme os interesses da organização. Dessa forma, a categoria de fatores políticos engloba os fatores relacionados aos interesses dos gestores, responsáveis pela decisão de implantação do modelo.

O Apoio da Cúpula, visto como um dos fatores preponderantes e mais importantes entre as agências - escore 6 em presença crítica -, se relaciona ao fornecimento de recursos e de respaldo, formal e informal, para a implantaçáo da gestão por competências. Os entrevistados se referem a este fator como um sinal de legitimação interna do processo que promove a colaboração dos demais gestores e dos servidores. Essa legitimação é importante para procedimentos da gestão por competências que requerem a participação de toda a organizaçáo, como o mapeamento de competências e a realização de avaliaçóes de desempenho. Conforme relatos das duas agências que atualmente aplicam aspectos da gestão por competências:

\footnotetext{
"[...] uma das maiores conquistas do projeto foi que nós conseguimos o suporte. [...] com os superintendentes que a gente teve $100 \%$ de adesão no projeto e aí, consequentemente dos servidores, a gente teve $92 \%$ de adesão dos servidores,
}

porque as lideranças valorizaram, porque a diretoria valorizou." (Coordenador, Agência 5)

"O Projeto foi desenvolvido pela Gerência de Recursos Humanos, que teve total apoio da Diretoria Colegiada” (Analista, Agência 1)

Como subproduto da importância do apoio político, a Rotatividade dos Gestores é um fator relativamente frequente e relevante entre as agências, especialmente naquelas em processo de estruturação. A rotatividade de gestores no setor gestáo de pessoas e, em geral, nos demais níveis superiores da hierarquia, é vista como um fator que altera a base de suporte às instituiçốes (SCHOMMER, 2003), sendo que, no caso das agências, houve prejuízo à continuidade de implantação do modelo.

“Mudou a gestão no início [do ano]. Então com isso acabou que todo trabalho está sendo retomado, muda algumas coisas.” (Analista, Agência 8)

Uma alta rotatividade nos cargos gerenciais pode indicar uma baixa propensão à institucionalização de inovaçóes. Especialmente em seus estágios iniciais, quando há uma sujeiçẫo maior ao arranjo político. Apenas estruturas em estados de institucionalização mais avançados são, provavelmente, menos prejudicadas pela mudança de gestores, já que estão mais bem incorporadas à cultura organizacional.

\subsection{Fatores Organizacionais}

O processo decisório inerente à mudança organizacional, segundo a Teoria Institucional, ocorre por uma série de fatores condicionados pelos recursos e características internas à organização, dentre os quais, vantagens na adoçáo da inovação (TOLBERT; ZUCKER, 1999) e baixo desempenho das estruturas já estabelecidas (MACHADO-DASILVA; GONÇALVES, 1999). Observou-se que a implantaçáo do modelo nas agências depende do alcance de um patamar de desenvolvimento organizacional para o qual convirjam fatores estruturais, humanos, processuais e estratégicos. Conforme ressalta Schommer (2003), por mais determinantes que sejam os mecanismos isomórficos, a institucionalização de uma nova estrutura requer condições políticas, econômicas e gerenciais para que ocorra de forma efetiva, evidenciando a influência de recursos e capacidades internas, como enfatiza a VBR, no alcance da institucionalização. 
Essa consolidação organizacional ainda está em curso em muitas agências. Em alguns casos, o Quadro de Servidores é ainda incipiente e os processos de reformulação da Estrutura organizacional ocorrem de forma recorrente. Esses aspectos acabam por resultar na imposiçấo de mudanças constantes no processo de implantação do modelo de gestão de pessoas em questão. Assim, conforme relato dos entrevistados, algumas agências chegam a evitar a definição de suas competências, por considerarem este um procedimento precipitado, sujeito a mudanças iminentes, que levarão ao descarte ou à obsolescência do trabalho de mapeamento. Nas agências cuja estrutura organizacional encontra-se mais consolidada, outros fatores foram constatados, como o porte da organização e o grau de departamentalização e verticalização, elementos que podem influenciar a velocidade da implantação do modelo.

Em relação a técnicas gerenciais estabelecidas nas organizações consultadas, a realização de um Mapeamento de Processos seria capaz de fornecer subsídios para definição de competências organizacionais, setoriais e individuais com base no conhecimento dos processos-chave da organização. A existência de um processo deliberado e racional de Planejamento Estratégico emergiu como um fator condicionante, reconhecido pelas agências, para a implantação da gestão por competências. Destacase que este foi o único fator reconhecido de forma unânime - escore $10 \mathrm{em}$ presença -, corroborando a necessidade do fator coerção normativa, assim como os fundamentos da gestão por competências como um modelo estratégico cujo propósito essencial consiste na vinculação das competências individuais aos objetivos e metas da organização (PRAHALAD; HAMEL, 1990).

Os demais aspectos organizacionais identificados denotam a percepção do modelo como Solução Prática de necessidades organizacionais. Especificamente, esse fator relaciona-se à adesão instrumental de gestores e servidores e, portanto, pode ser enquadrado como pertencente à fase de habitualização integrante da perspectiva processual de institucionalização desenvolvida por Tolbert e Zucker (1999). Já o fator Integração com outras organizaçôes representa a suscetibilidade das agências de adotarem práticas por meio do intercâmbio de informaçôes e conhecimento, demonstrando mecanismos de isomorfismo mimético ou normativo (DIMAGGIO; POWELL, 1991).

\subsection{Fatores Técnico-Metodológicos}

Nesta categoria se classificam os relatos que envolveram a discussão acerca dos métodos, técnicas e abordagens empregados durante a concepção, mapeamento e aplicação da gestáo por competências nos órgãos. Essa categoria representa bem os mecanismos do isomorfismo normativo por representar a conformidade de práticas difundidas em uma classe profissional (DIMAGGIO; POWELL, 1991), no caso, os profissionais de gestão de pessoas.

O fator Metodologia Utilizada é bastante predominante entre as agências, estando presente em nove dentre dez agências. Porém, possui baixa relevância, sendo considerado crítico por apenas uma delas, o que pode indicar um bom gerenciamento desse fator pelas agências. Para a fase de mapeamento, a maior parte dos problemas relatados se refere ao grande número de informaçôes a serem trabalhadas e a difícil transposiçáo de pressupostos teóricos para a administração pública, geralmente em função da sua ênfase no setor privado. O mapeamento é visto como um trabalho de cunho científico, como uma pesquisa, cujos métodos de aplicação devem ser adaptados à realidade da agência.

\footnotetext{
"Uma coisa é Gestão por Competências na iniciativa privada outra coisa é [...] no serviço público. São duas coisas diferentes, você tem que fazer essas adequaçóes." (Gerente, Agência 4)

"Por mais que a gente visitasse e visse o trabalho dos outros, nós terminamos fazendo uma coisa bem adequada a nossa realidade. [...] eu não sei como isso pode ser julgado fora. Mas a gente está assim, buscando um caminho nosso." (Analista, Agência 2)

“[...] eu nem sei se pode existir um modelo, eu acho que diretrizes sim, mas modelo eu acho que é difícil, porque cada realidade é uma.” (Analista, Agência 1)
}

Há uma tendência ao desenvolvimento de modelos adequados à realidade organizacional (CAPALDO; IANDOLI, ZOLLO, 2006), demonstrandose a dificuldade de um modelo comum, conforme preconizado por outros estudos (ORGANIZAÇÃO PARA A COOPERAÇÃO E DESENVOLVIMENTO ECONÔMICO, 2010a). Por outro lado, houve grande número de mençôes à metodologia desenvolvida e difundida pela Escola Nacional de Administra- 
ção Pública (ENAP). As visôes são divergentes quanto à aplicabilidade da metodologia desenvolvida pela ENAP, sendo que algumas agências a consideram insuficiente enquanto outras atribuem-lhe o sucesso do mapeamento. Não obstante, constatou-se uma ampla utilizaçâo de alternativas e inovaçôes adaptativas, indicando uma variedade de métodos de mapeamento e aplicação do modelo conforme as necessidades e contexto de cada Agência. Essa heterogeneidade metodológica, conforme Tolbert e Zucker (1999), reforça o enquadramento do processo de implementação do modelo de gestão por competências, como antes indicado, na etapa pré-institucional. Essa diversidade metodológica e a subsequente incerteza quanto aos seus resultados acabaram por suscitar a busca de apoio e orientação dos órgãos que instituíram legalmente essa nova política.

Assim, a maior parte das agências considera como fator crítico a Orientação e o Acompanhamento do Governo, por intermédio do Ministério do Planejamento, Orçamento e Gestão - MP e da ENAP. A condução do processo por órgãos centrais contribui como fator isomórfico normativo ao consolidar e legitimar a metodologia utilizada. Nas agências contempladas por uma orientação do Governo, relatouse um avanço significativo, mas, de maneira geral, há grande demanda para uma atuação maior dessas entidades. No entanto, aparentemente, há limites para essa atuação, que podem estar ligados a uma eventual falta de capacidade técnica das entidades para monitorar diversos órgãos isoladamente.

\footnotetext{
"Que o Governo crie também as ferramentas necessárias para a implementação dessas estratégias. Porque ele define e orienta, mas ele náo cria as ferramentas, então cada instituição tem que estar desenvolvendo suas ferramentas de um jeito, muitas vezes perdendo um tempo enorme" (Analista, Agência 2)
}

Muitas das críticas endereçadas ao Governo, nesse sentido, resultam da expectativa acerca do desenvolvimento de um sistema informatizado que permita um gerenciamento eficiente do modelo de gestão de pessoas por competências. Conforme resultados antes evidenciados, $60 \%$ das agências consideram necessária a utilização de um Sistema de Gestão informatizada para se operar processos com base em competências, sendo esse fator crítico para $40 \%$ das agências. Para os entrevistados, este sistema contri- buiria, ainda, para a uniformização de conceitos, metodologias e para a geraçáo de uma base de dados, a partir da definição de critérios homogêneos, comuns aos diversos órgãos pesquisados.

\subsection{Fatores Culturais}

Essa categoria se atém à reação dos servidores e gestores às mudanças implicadas na adoção do modelo de gestão por competências. Nesse ínterim, um dos fatores identificados de forma predominante e de bastante relevância refere-se à necessidade de Sensibilização de gestores e servidores, com vistas a informá-los acerca das implicaçóes do modelo e obter seu suporte. Sobre tal aspecto, Tolbert e Zucker (1999) caracterizam o consenso como um fator de institucionalização, referido, na obra de Apel e Bitencourt (2008), como resultado de um processo de produção coletiva ou de construçáo social. Sob outro prisma, Silva e Godoi (2006) também demonstram a importância da construção social como parte de um processo de aprendizagem organizacional, tido como a linha mestra para institucionalizaçâo da gestâo por competências. Em ambas as perspectivas, conforme Schommer (2006), essa visão relativiza concepçôes indevidamente atribuídas ao isomorfismo, de que as inovaçóes seriam adotadas de forma direta, sem crítica ou adaptação. Em última análise, uma inovação passa por uma valoração dos atores envolvidos, que a incorporam conforme seus interesses, de forma que a sua sensibilização permite, portanto, a evolução negociada do processo de institucionalização.

A formação de grupos de resistência, previsto como parte dos obstáculos à institucionalização (APEL; BITENCOURT, 2008; TOLBERT; ZUCKER, 1999), estaria relacionada, assevera Schommer (2003), à herança institucional ou à coexistência de pressupostos conflitantes de estruturas em transição, como é o caso da transição do modelo burocrático para o gerencial no setor público. Nas agências, o fator Resistência se manifesta na dificuldade de se instituir uma cultura de planejamento, baseada em critérios objetivos. Conforme entrevistados, esse fator está ligado à redução da discricionariedade de supervisores no que toca à gestáo de seus subordinados:

\footnotetext{
"Quando você trabalhar a gestão por competências, dependendo do gestor, ele vai se sentir preso. Porque [...] não vai poder ser tão arbitrário igual ele é hoje" (Gerente, Agência 4)

"Agora, há um medo muito grande, de uma for-
} 
ma geral, porque quando você trabalha por gestão por competências e a implanta, as coisas ficam muito claras. Então, de alguma forma, você tira poder. (Coordenadora, Agência 7)

Um terceiro fator de grande relevância e difusão nas agências foi identificado na Expectativa de Resultados, associada à implantaçáo do modelo de gestáo por competências. Talvez resultante da presença de outros tantos fatores descritos neste estudo, esse fator emerge de percepçóes discrepantes acerca da gestáo por competências, cuja retórica, apesar de almejar resultados e benefícios vantajosos para os atores implicados, não encontra amparo técnico, organizacional etc. para ser definitivamente exercitada. Em muitos casos, essa baixa expectativa se relaciona ainda, em muitas agências, à tradicional imagem do setor de gestão de pessoas como uma área desacreditada, fragmentada e reativa, associada a projetos sem resultados práticos ou mal sucedidos:

"Tem uma expectativa assim quanto ao resultado final desse trabalho que ele acha assim, que é mais uma burocracia, mais um trabalho que ele vai fazer que não vai sair do papel.” (Analista, Agência 10)

Com efeito, um processo de mapeamento de competências deve ser iniciado apenas quando se busque efetivá-lo através de práticas de gestão de pessoas, ou seja, quando se busquem resultados práticos. A maioria das agências que ainda não realizaram o mapeamento adota a premissa de que náo se deve investir na divulgaçáo do modelo enquanto não houver condiçóes de se gerar resultados concretos. Essa medida de cautela está ligada, portanto, ao gerenciamento da expectativa acerca dos resultados do modelo.

\subsection{Fatores Relacionados aos Recursos Humanos do Projeto}

A última categoria de fatores composta se relaciona aos aspectos internos do setor de gestão de pessoas e com os agentes implicados diretamente na condução do processo de implantaçấo da gestão por competências. Um primeiro fator recorrente e de relativa importância é a Capacitação e o preparo técnico dos servidores do setor de gestão de pessoas. A busca pelo domínio técnico do processo é feita majoritariamente por meio de cursos formais, mas também, através de auto-aperfeiçoamentos e visitas técnicas a órgãos com práticas de sucesso nesse sentido. Compreende também a capacidade de se propor o projeto aos gestores da agência dado que, em muitos casos, a área de gestão de pessoas é responsável pela busca de apoio político por meio da defesa dos benefícios do processo junto aos dirigentes superiores. Tal formação geraria condições de continuidade ao projeto, de forma a garantir sua execuçáo ao longo do tempo por intermédio de equipes preparadas e tecnicamente autônomas.

Neste contexto, as agências buscam a designação de pelo menos um servidor que, após se submeter a processos formais e informais de especialização, atue como multiplicador na disseminação de valores, procedimentos e técnicas necessários à implementação do modelo de gestão por competências. Esse servidor termina por coordenar os demais atores implicados no projeto, geralmente todos os servidores do setor da unidade responsável. Assim, o fator de Mobilização dos funcionários do setor de gestão de pessoas, expresso por algumas agências, mostrou-se como um fator a ser considerado. Destaca-se o fato de que essa mobilização, se não estimulada, durante o processo de mapeamento ou aplicação da gestão por competências, mantém o processo de implantaçáo isolado na área de capacitaçáo, ou onde esteja sendo realizado, restringindo as possibilidades de alinhamento sistêmico com outras atividades, que constitui parte das premissas básicas de qualquer modelo estratégico de gestão de pessoas.

A questão exposta, contudo, é que o mau dimensionamento das equipes de trabalho ante este processo de implementação, considerando a atual fase de reestruturação que atravessam as agências, acaba por limitar a mobilização exigida para a sua consecução. A maioria das agências, nesse sentido, dispõe de equipes reduzidas nas áreas de capacitação que, em função do teor do decreto citado, naturalmente se tornam responsáveis pela implantação da gestâo por competências. Essa é considerada uma dificuldade crítica por $60 \%$ das agências. Em consonância com os pressupostos da VBR, como enfatizam Wright e McMahan (1992), a implantação de estratégias bem sucedidas de gestáo de pessoas está condicionada ao domínio de uma série de competências pela base da própria estrutura de pessoas das unidades de recursos humanos.

\subsection{Análise de fatores de maior predominância e relevância}

Por fim, a análise geral dos fatores identificados serve ao propósito de se demonstrar a complexidade do processo de implantação da gestão por competências. Os fatores de maior presença podem identificar 
Tabela 4. Fatores de maior presença nas agências.

\begin{tabular}{clc}
\hline Categoria & \multicolumn{1}{c}{ Denominação dos Fatores } & Presença \\
\hline Organizacional & Existência de planejamento estratégico & $\mathbf{1 0}$ \\
\hline Normativo-Legal & Legislação & $\mathbf{9}$ \\
\hline Técnico-Metodológicos & Metodologia Utilizada & $\mathbf{9}$ \\
\hline Cultural & Sensibilização gestores e servidores & $\mathbf{9}$ \\
\hline Recursos Humanos & Capacitação e domínio técnico do processo & $\mathbf{9}$ \\
\hline
\end{tabular}

Tabela 5. Fatores de maior importância nas agências.

\begin{tabular}{ccc}
\hline Categoria & Denominação dos Fatores & $\begin{array}{c}\text { Presença } \\
\text { Crítica }\end{array}$ \\
\hline Político & Apoio da Cúpula & $\mathbf{6}$ \\
\hline Técnico-Metodológicos & Orientação e Acompanhamento do Governo & $\mathbf{6}$ \\
\hline Cultural & Expectativa de Resultados & $\mathbf{6}$ \\
\hline Recursos Humanos & Tamanho da Equipe de Trabalho & $\mathbf{6}$ \\
\hline
\end{tabular}

as ênfases em geral do setor de regulação nos seus processos de implantação. O maior número de presenças foi identificado nos fatores elencados na Tabela 4.

Depreende-se que as agências atentam-se principalmente para os pressupostos normativos para implantação da gestão por competências - Planejamento Estratégico e Legislação - e buscam aperfeiçoar a concepção de seus modelos de gestão por competências e transmiti-los ao restante da organização. Em geral estáo buscando capacitação, adequaçôes e conformidade metodológicas, legitimidade interna e alinhamento com objetivos institucionais evidenciando um processo de preparação para implementação. Os fatores de maior importância crítica, conforme a opinião dos entrevistados, estáo enumerados na Tabela 5 .

A Tabela 5 demonstra que os setores de gestáo de pessoas consideram críticos aqueles fatores que se encontram fora de sua competência e com os quais mantêm relativo grau de dependência. Os fatores demonstram um processo de legitimação, no qual estão implicados três agentes interconectados. Primeiramente, a presença do Governo do ponto de vista da orientação metodológica e do fornecimento de tecnologia, validando os métodos aplicados e a relevância estratégica da política de desenvolvimento. Em segundo lugar, os dirigentes superiores, que fornecem amparo político e relevância para o processo. Por fim, como resultado final de uma cadeia de legitimação, deve ser gerada uma expectativa positiva de resultados que implique a contribuição de gestores e servidores. O fator Tamanho da Equipe reflete um último nível no qual a importância atribuída do processo deveria impactar: o adequado dimensionamento de uma equipe para o projeto.
Assim, os fatores refletem fundamentos e contingências-chave para a implantaçáo do modelo de gestão por competências nas agências reguladoras e estáo associados aos mecanismos de institucionalização previstos por Tolbert e Zucker (1999). A relativa distribuição dos fatores predominantes e relevantes em diferentes categorias atesta o caráter multidimensional desse processo, muitas vezes não abrangido completamente pela literatura. Depreende-se que a configuração desses fatores-chave nas agências pode ter sido a razão para os diferentes graus de implementação do modelo.

\section{CONSIDERAÇÓES FINAIS}

O estudo apresentado buscou analisar o processo de implantação da gestáo por competências e seus fatores condicionantes no âmbito das agências reguladoras federais. Considera-se que foi atendido o objetivo principal da pesquisa, obtendo-se uma caracterização dos fatores determinantes na implantação do modelo nas agências. Observou-se nos resultados a correspondência com aspectos da teoria institucional que, ao contribuir para a compreensão do fenômeno, demonstrou sua utilidade em estudos organizacionais, como preconizado por Apel e Bitencourt (2008). Acrescenta-se a isso a convergência da teoria institucional com aspectos complementares da Visão Baseada em Recursos, ao constatar-se o que o grau de desenvolvimento organizacional e a existência de um arranjo adequado de recursos internos condicionam a institucionalização da gestáo por competências, não obstante a magnitude das pressóes ambientais. Configura-se, portanto, uma complexa combinação de 
elementos organizacionais e institucionais que geram diferentes trajetórias e capacidades de implantaçáo do modelo de competências em cada Agência.

Para além do delineamento e corroboração de fatores organizacionais, propóe-se como principal contribuição do presente estudo a maior compreensão dos fatores institucionais específicos do setor público. A legislação de pessoal demonstrou-se um importante fator institucional. Atualmente, os subsistemas de gestão de pessoas funcionam separadamente nas organizações, prejudicando a consecução de um dos principais pressupostos para a efetividade da gestáo por competências, qual seja, a integração horizontal de práticas de gestão de pessoas (ORGANIZAÇÃO PARA A COOPERAÇÃO E DESENVOLVIMENTO ECONÔMICO, 2010a). Não obstante, as Agências buscam implementar seus modelos, resultando em versôes aproximadas de um sistema de capacitação planejado e de um sistema de avaliação de desempenho focado em resultados, porém ainda incipientes em relaçáo ao potencial de um modelo de competências.

A forma de atuação do Governo na condução da política também emerge como um fator institucional relevante. As agências demonstram grande dependência com relação à atuação dos órgãos centrais de Governo no sentido de se ajustar dispositivos legais e fornecer ferramentas e métodos para aplicação da gestão por competências. No entanto, evidenciou-se uma participação do Governo considerada insuficiente para prover a demanda das agências na implantação do modelo. A discussão a que leva essa constatação é de que cabe ao Governo decidir o grau de vinculação normativa que se deseja estabelecer para conduzir a modernização do aparelho de Estado. Em muitos aspectos, um menor grau de regulamentaçáo permitiria maior flexibilidade e menor dependência técnica para que as organizações públicas, na medida de seu desenvolvimento, instituíssem as práticas gerenciais que melhor lhes aprouvessem, tendo como instrumentos de controle diretrizes e resultados, definidos em contratos gestão, por exemplo. Por outro lado, se é almejado um maior nível de regulamentaçâo e controle, o Governo deve ser capaz de propiciar a consistência interna das normas e de possuir capacidade para atuar como orientador de suas instituiçóes para realização das reformas que deseje implantar. Entre esses dois papéis, com diferentes níveis de centralização, deve ser definido aquele que servirá como base e como passo inicial na formulação de uma política consistente para a reforma gerencial. Considerando-se o teor tradicionalmente centralizado das práticas de gestão de pessoas no Governo Federal, depreende-se como solução imediata a criação de um modelo de gestáo por competências comum a todos os órgãos, portanto centralizado, como ocorre em diversos países onde a experiência foi bem sucedida (ORGANIZAÇÃO PARA A COOPERAÇÃO E DESENVOLVIMENTO ECONÔMICO, 2010a).

A baixa quantidade de estudos específicos que busquem contribuir para um melhor desenvolvimento do setor público no Brasil leva a muitas recomendações que podem ser feitas a partir do presente trabalho. Em tese, cada um dos fatores identificados nesta pesquisa pode levar a questóes específicas de investigação. A abordagem da presente pesquisa possui limitaçôes, especialmente no que se refere à desconsideraçấo da visão dos órgãos centrais de Governo e dos demais gestores e servidores das agências. Não obstante, tal aspecto tem sido complementado por estudos recentes, tal como o realizado por Camóes e Meneses (2016). Além disso, o método de levantamento aplicado neste estudo é suscetível à interpretação do pesquisador e à arbitrariedade dos entrevistados na atribuiçáo de relevância aos fatores destacados. Recomenda-se, portanto, a condução de pesquisas diversificadas em termos de delineamentos, métodos, abordagens, procedimentos e técnicas, com vistas à identificação mais confiável de fatores que resultem em uma melhor definição dos elementos de institucionalização ora reunidos, assim como a ampliação do universo amostral da pesquisa, com inclusão de diferentes organizações públicas e servidores atuantes em diferentes posições e cargos.

Tais recomendaçôes para a continuidade dos estudos sobre o tema talvez possibilitem a formulação de políticas governamentais, especialmente no que se refere a um processo de normatização da legislação de pessoal mais consistente e integrativo, que provejam melhores condiçôes de institucionalização da gestão por competências na administração pública.

\section{REFERÊNCIAS}

APEL, H.; BITENCOURT, C. C. Gestão de Pessoas por Competência: Institucionalização, Possibilidades e Dificuldades Implícitas nas Relaçoes Trabalhistas Brasileiras. Organizaçóes e Sociedade, Salvador, v.15 n.46, p.175-193, 2008.

$\mathrm{BACH}, \mathrm{S}$. Human resource management in public sector. In: WILKINSON, A. et al. (Org.). The sage handbook 
of human resource management. London: Sage Publications, 2010.

BARDIN, L. Análise de conteúdo. Trad. Luís Antero Reto e Augusto Pinheiro. Lisboa: Ediçóes 70, 2009.

BRASIL. Decreto no 5.707, de 23 de fevereiro de 2006. Institui a política e as diretrizes para o desenvolvimento de pessoal da administração pública federal direta, autárquica e fundacional, e regulamenta dispositivos da Lei no 8.112, de 11 de dezembro de 1990 .

BRANDÃO, H. P.; BAHRY, C. P. Gestão por competências: métodos e técnicas para mapeamento de competências. Revista do Serviço Público, Brasília, v.56, n.2, p.179-194, 2005.

BRANDÃO, H. P.; GUIMARÃES, T. A. Gestão por Competências e gestấo de desempenho: tecnologias distintas ou instrumentos de um mesmo constructo? Revista de Administraçáo de Empresas, São Paulo, v.41, n.1, p.8-15, 2001.

CAMÓES, M. R. S.; MENESES, P. P. M. Gestáo de Pessoas no Governo Federal: Análise a partir da Implementação da Política Nacional de Desenvolvimento de Pessoal.. Brasília: Enap. (Cadernos Enap, n. 45), 2016.

CAPALDO, G.; IANDOLI, L.; ZOLLO, G. A situationalist perspective to competency management. Human Resource Management, v. 45, n. 3, p. 429-448, fall, 2006.

DiMAGGIO, P. J.; POWELL, W. W. The iron cage revisited: Institutional isomorphism and collective rationality in organizational fields. In: POWELL, W.W.; DiMAGGIO, P. J. The new institutionalism in organizational analysis. Chicago: The University of Chicago Press, 1991.

FONSECA, D. R. et al. Autonomia para gestão estratégica de pessoas no setor público federal: perspectivas de análise e agenda de pesquisa. Revista de Administraçáo Pública, v. 47, p. 1451-1475, 2013.

GELIS FILHO, A. Análise comparativa do desenho normativo de instituiçôes reguladoras do presente e do passado. Revista de Administraçáo Pública, Rio de Janeiro, v.40, n.4, 2006.

JACKSON, S.E; SCHULER, R.S.; JIANG, K. An Aspirational Framework for Strategic Human Resource Management, The Academy of Management Annals, v.8, n.1, p. 1-56, 2014.

LACOMBE, B. M. B.; CHU, R. A.; Políticas e práticas de gestão de pessoas: As abordagens estratégica e institucional. Revista de Administração de Empresas, São Paulo, v.48, n.1, 2008.
MACHADO-DA-SILVA, C.L; GONÇALVES, S. A. Nota Técnica: A Teoria Institucional. In: ___ Handbook de Estudos Organizacionais: Modelos de Análise e Novas Questões em Estudos Organizacionais. São Paulo: Atlas, 1999. p.220-226.

ORGANIZAÇÃO PARA A COOPERAÇÃO E DESENVOLVIMENTO ECONÔMICO. Avaliaçáo da Gestáo de Recursos Humanos no Governo: Relatório da OCDE Brasil: Governo Federal (Portuguese version). [S.l.]: OECD Publishing, 2010a.

Managing competencies in Government: State of the art practices and issues at stake for the future. [S.I.]: OECD, 2010b.

PAAUWE, J.; BOSELIE, P. Challenging 'strategic HRM' and the relevance of the institutional setting. Human Resource Management Journal, v.13, n.3, p.56-70, 2003.

PORTER, M. E. Competitive strategy. New York: Free Press, 1980.

PRAHALAD, C. K.; HAMEL, G. Competindo pelo futuro: Estratégias inovadoras para obter o controle do seu setor e criar os mercados de amanhã. São Paulo: Elsevier: 2005.

SILVA, A. B.; GODOI, C. K. O processo de aprendizagem como balizador para o desenvolvimento de um modelo de competências para uma empresa do setor elétrico. Revista do Centro de Ciências Administrativas, Fortaleza, v.12, n.1, p.62-75, 2006.

SCHOMMER, P. C. Gestão pública no Brasil: Notícias do teatro de operaçóes. Revista de Administraçáo de Empresas, São Paulo, v.43, n.4, 2003.

TOLBERT, P. S.; ZUCKER, L. G. A institucionalização da teoria institucional. In: CLEGG, S.R et al. Handbook de estudos organizacionais: Modelos e novas questôes em estudos organizacionais. São Paulo: Atlas, 1999. v.1, p.196-219.

VERGARA. S. C. Métodos de pesquisa em Administração. São Paulo: Atlas, 2006.

WRIGHT, P. M.; McMAHAN, G.C. Theoretical perspectives for strategic human resource management. Journal of management, v.18, n.2, p. 295-320, 1992. 